\title{
Focus of attention and online demonstration effects on temporal error and muscle activation
}

\section{Efeitos do foco de atenção e demonstração online no erro temporal e na ativação muscular}

\author{
Tércio Apolinário-Souza ${ }^{1}$ \\ (D) https://orcid.org/0000-0002-2136-0238 \\ Herbert Ugrinowitsch² \\ (D) https://orcid.org/0000-0003-0317-1940 \\ Carlos Eduardo Campos ${ }^{2}$ \\ (D) https://orcid.org/0000-0003-2492-2256 \\ Lucas Túlio de Lacerda $2,3,4,5$ \\ (D) https://orcid.org/0000-0002-0735-8131 \\ Frank Douglas Tourino ${ }^{2}$ \\ (D) https://orcid.org/0000-0002-6513-3045 \\ Lucas Savassi Figueiredo² \\ (D) https://orcid.org/0000-0001-5853-4978 \\ Guilherme Menezes Lage ${ }^{2}$ \\ (D) https://orcid.org/0000-0001-8296-3676
}

Abstract - The purpose of the present study was to examine whether there would be performance differences between external and internal focus of attention conditions and an online demonstration condition, and if these differences would be observed at a neuromuscular level through EMG analysis, in addition to traditional outcome measures. We hypothesized that under the demonstration condition participants would perform better than under external and internal focus conditions. We also hypothesized that demonstration condition would show smaller EMG activity than external and internal focus conditions. Furthermore, we hope to replicate the benefits of external focus in relation to internal focus, both in outcome and product measures. Six male participants performed a bilateral leg extension under internal focus of attention, external focus of attention and online demonstration conditions. Muscular contractions goal times were set for concentric muscle action (4 seconds) and eccentric muscle action (2 seconds). An electrogoniometer was used to record muscular activation (production measures), and temporal error was used to observe performance (outcome measures). Results showed that online demonstration condition obtained better performance than external focus condition and a reduced muscular activation. However, differences between internal focus and the other experimental conditions were not found. These findings advance in the understanding mechanisms underpining the focus of attention, such as proposed by Constrained Action Hypothesis.

Key words: Electromyography; Exercise; Motor activity.

Resumo - O objetivo do presente estudo foi avaliar as diferenças no desempenho entre as condições de foco de atenção externo e interno e uma condição de demonstração online. Adicionalmente, se essas diferenças seriam observadas em um nivel neuromuscular por meio da análise EMG, além das medidas de resultados tradicionais. Foi levantada a hipótese que sob a condição de demonstração os participantes teriam um desempenho melhor do que sob as condiçöes de foco externo e interno. Também foi levantado a bipótese que a condição de demonstração apresentaria menor atividade EMG do que as condições de foco externo e interno. Além disso, esperava-se corrobora os benefícios do foco externo em relação ao foco interno, tanto nas medidas de resultado quanto de produto. Seis participantes do sexo masculino realizaram uma extensão de perna bilateral nas condiçôes: foco de atençâo interno, foco de atenção externo e condiçôes de demonstração online. Os tempos de meta de contrações musculares foram definidos para ação muscular concêntrica (4 segundos) e ação muscular excêntrica (2 segundos). Um eletrogoniômetro foi usado para registrar a ativação muscular (medidas de produção) e o erro temporal foi usado para observar o desempenho (medidas de resultado). Os resultados mostraram que a condiçẫo de demonstração online obteve melhor desempenho do que a condição de foco externo e uma ativação muscular reduzida. No entanto, não foram encontradas diferenças entre o foco interno e as outras condiçôes experimentais. Esses achados avançam no entendimento dos mecanismos que sustentam o foco de atenção, como o proposto pela Constrained Action Hypothesis.

Palavras-chave: Atividade motora; Eletromiografia; Exercício físico.
1 Universidade do Estado de Minas Gerais. Ibirité, MG. Brazil

2 Universidade Federal de Minas Gerais. Belo Horizonte, MG. Brazil

3 Universidade do Estado de Minas Gerais. Divinópolis, MG. Brazil

4 Pontifícia Universidade Católica de Minas Gerais. Belo Horizonte, MG. Brazil

5 Centro Federal de Educação Tecnológica de Minas Gerais. Belo Horizonte, MG. Brazil

Received: April 01, 2019 Accepted: February 15, 2020

How to cite this article Apolinário-Souza T, Ugrinowitsch $\mathrm{H}$ Campos CE, Lacerda LT, Tourino FD, Figueiredo LS, Lage GM. Focus of attention and online demonstration effects on temporal error and muscle activation. Rev Bras Cineantropom Desempenho Hum 2020, 22:e62893. D0l: http://dx.doi. org/10.1590/1980-0037.2020v22e62893

Copyright: This work is licensed under a Creative Commons Attribution 4.0 International License. 


\section{INTRODUCTION}

The focus of attention is a variable that affects motor performance and learning. In terms of direction, the focus of attention can be directed to the movement itself, known as internal focus, or directed to the effect this movement on the environment, known as external focus ${ }^{1,2}$. Wulf et $\mathrm{al}^{2}$ demonstrated in two experiments that the external focus condition is more effective for performance when compared to internal focus. Subsequent studies confirmed the benefits of the external focus condition in other tasks - for example, in basketball ${ }^{3}$, golf shots $^{4}$, ballet pirouette ${ }^{5}$, and baseball batting ${ }^{6}$. The explanation for the benefits of external focus when compared to internal focus comes from the predominant use of unconscious or automatic processes to control movements when attention is externally directed (Constrained Action Hypothesis) ${ }^{7}$. Inversely, when individuals' attention is directed to their own body movements - internal focus - individuals become more conscious of the need to control their movements. A variety of studies support this notion ${ }^{8-11}$.

Studies have generally used outcome measures when investigating attentional focus. However, some studies have used production measures, such as the neuromuscular level, through measures such as electromyography (EMG), to infer how movements were organized by the nervous system when individuals directed attention under external and internal focus conditions ${ }^{12}$. Specifically, it is expected that if an external focus results in greater automaticity than an internal focus, smaller EMG activity would be found ${ }^{13,14}$. That assumption is based on the proposition that an external focus promotes greater coherence between sensory input and motor output ${ }^{13}$. Greater coherence between sensory input and motor output generates a more discriminate motor unit recruitment, allowing the motor system an energy economy and less "noise" to perform movements ${ }^{15}$. The first study to support this notion was Vance et al. ${ }^{17}$, where participants performed biceps curls under two attentional focus conditions: directing their attention to the curl bar or to their forearm, external and internal focus of attention respectively. Results showed that in the external focus condition EMG activity was reduced when compared to internal focus.

Another way to direct individual's attention may be through the use of an external reference model or demonstration, during the execution of the task ${ }^{16}$. This demonstration allows directing individual's attention towards critical aspects of the task, instead of the muscles associated with movement execution ${ }^{17}$, which affects both motor skills acquisition by inexperienced subjects and motor performance in experienced subjects ${ }^{18}$. Such online reference is not clearly associated with the individual's movement production, as it is the case when attention is directed through internalexternal focus. Using an online demonstration may allow the observer to extract information from the model, external to your body, acting as another way to direct attention ${ }^{17}$. This condition may be as effective as or even more effective than an external focus condition in order to allow 
more automatic movements to be carried out. This may occur because when the individual is under the influence of online demonstration he is less concerned with the effect that his movement has on the environment, as in an external focus condition, which leads to more unconscious or automatic movement control in relation to others ways to direct attention (internal and external focus ${ }^{16}$. Besides, it allows the individual to create an appropriate reference regarding the $\operatorname{task}^{19}$ and to provide basis for movement corrections, when presented concurrently or even after task execution ${ }^{20}$, which are demonstration traditional benefits. Thus, in addition to the effects associated with the external focusing of attention, online demonstration may allow learners to benefit from its traditional effects when learning new skills or improving an already skillful behavior. However, this issue still needs to be investigated, since there are no studies in the literature, to the authors' knowledge, that investigated the effects of attentional focus and online demonstration.

The purpose of the present study was to examine whether there would be performance differences between external-internal focus conditions and online demonstration, and if these differences could be observed at a neuromuscular level, through EMG analysis, in addition to traditional outcome measures. We hypothesized that under the demonstration condition participants would perform better than under external and internal focus conditions. We also hypothesized that demonstration condition would show smaller EMG activity than external and internal focus conditions. Furthermore, we hoped to replicate the benefits of external focus in relation to internal focus, both in outcome and product measures. Participants performed leg extension under (a) internal focus, (b) external focus and (c) online demonstration conditions. A within-participant design was adopted in this study. The EMG activity was recorded from vastus lateralis muscle.

\section{METHOD}

\section{Participants}

Participants were six male university students (age $=24.1 \pm 5$ years) who were engaged in a strength-training program for at least six months uninterruptedly. All participants declared right footedness. The sample was defined using the software $G^{*}$ Power (version 3.1) using data regarding temporal error from a pilot study. The software indicated a sample size of six subjects (critical $F=5.14$ ), setting the power of the tests to $95 \%$.

All study's procedures were conformed to the standards set by the Declaration of Helsinki (2014 version) for studies involving human subjects. A local ethics committee approved all study's procedures (CAAE: 64956217.6.0000.5149), and subjects provided informed consent after receiving a full explanation of the study.

\section{Apparatus, Task, and Procedure}

Participants performed a bilateral leg extension weighted with mass 
equivalent to $30 \%$ of their estimated maximum force. To determine this value, each participant underwent a strength assessment consisting of a one repetition maximum test (1RM). $1 \mathrm{RM}$ was defined as the maximum amount of weight that the participant could successfully lift from a 100 degrees (beginning of concentric muscle action) to a 30 degrees position (end of concentric muscle action), at full extension, and return to starting position, but was unable to successfully complete a second contraction. After a successful execution participants were provided five minutes to rest between each new level of resistance presented, and were allowed up to six trials for each level. Following the five minutes break, participants completed the knee extension repetitions with weights ranging from 10 to $15 \mathrm{~kg}$ increments. When approaching their maximum, weight increments were lower, from 1 to $5 \mathrm{~kg}$ until reaching $1 \mathrm{RM}$. The $1 \mathrm{RM}$ test was carried out 48 hours before the execution of experimental conditions (internal focus, external focus and demonstration) ${ }^{21}$.

Each Participant performed the bilateral leg extension under internal focus of attention, external focus of attention and online demonstration. All individuals received a demonstration by watching the video model before the execution of the experimental conditions. Participants performed six repetitions under each condition with a specific timing goal for each action - extension and flexion. The concentric muscle action had to be performed in 4 seconds and the eccentric muscle action had to last 2 seconds. Under the internal focus condition, participants were instructed to concentrate on their thigh muscles during movement execution. These participants performed the task blindfolded, to prevent them to extract any external references available from the environment during the execution of the task. Under the external focus condition, participants were instructed to concentrate in the mirror that reflected the movement performed during the execution. The mirror was positioned on the right side of the participant and was individually adjusted so that eachparticipant could visualize the entire movement. In the online demonstration condition, a computer monitor was placed in front of the participant, which watched a video of the movement execution concurrently to task execution. The same video was used for all volunteers. In this video, the movement shown to participants was performed by a model with the same timing goal of the task ( $4 \times 2$ seconds) and was recorded in the sagittal plane. Under this condition participants were instructed to direct their attention to the model observed in the video, and to follow the same temporal pattern of movement performed on the monitor. The amplitude of the movement was preset and standardized for all conditions. The three experimental conditions (internal focus of attention, external focus of attention and online demonstration) were randomized and the order among participants was counterbalanced. The experimental design is shown in Figure 1.

An electrogoniometer (Noraxon, São Paulo, BR) was used to record the concentric and eccentric muscular contractions of both legs during task execution. Surface-mounted $\mathrm{Ag} / \mathrm{AgCl} \mathrm{EMG}$ electrodes were positioned 
A

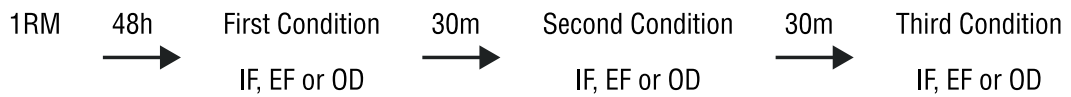

B

Internal focus

External focus

Online demonstration

"Concentrate on your tigh muscles"

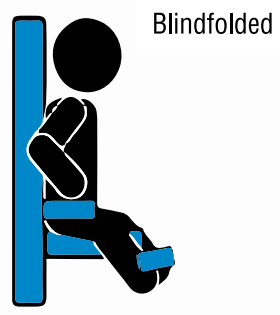

6 repetitions

$30 \%$ of maximum force
"Concentrate in the mirror"

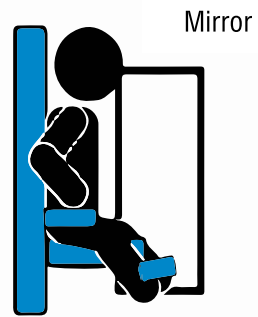

6 repetitions

$30 \%$ of maximum force
"Concentrate in the video"

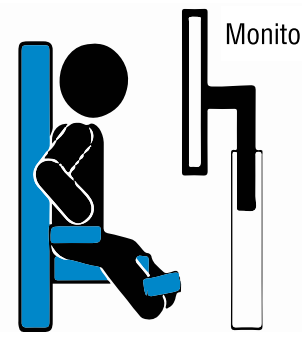

6 repetitions

$30 \%$ of maximum force

Figure 1. Schematic representation of the experimental design (A) and conditions: internal focus, external focus and online demonstration (B).

Note: IF = internal focus. $E F=$ external focus. $O D$ = online demonstration.

on the participants' skin in vastus lateralis muscle (recommendations of SENIAM). A common electrode was positioned on patella of the right knee. Participants were instructed to perform a bilateral leg extension at a weight that they could not lift - maximal voluntary isometric contraction (MIC) - at $60^{\circ}$, position with high torque ${ }^{22}$. The EMG magnitude during the MIC was used to normalize EMG magnitudes as a percentage of MIC for later stages of data collection. EMG data were sampled at a $1000 \mathrm{~Hz}$ frequency by using Noraxon Myoresearch,version 2.0 software (Noraxon, U.S.A, Scottsdale, AZ) ${ }^{21}$.

Participants performed three sets of six repetitions of the bilateral leg extension under each condition, resulting in a total of 18 repetitions. The order of conditions was counterbalanced between participants. They were given 5 min rest periods between each of the MIC trials and 30 min rest periods between each experimental condition (internal focus, external focus and demonstration).

\section{Data Analysis}

Processed EMG data recorded during the task was normalized with EMG values recorded during the MIC. Electrogoniometer data was filtered by a Butterworth lowpass filter $(\mathrm{f} \mathrm{c}=50 \mathrm{~Hz}), 1$ st order and smoothing data via RMS (root mean square) with a 50 ms window ${ }^{21}$.

Dependent measures included temporal error of movement and root mean square (RMS in percentage of MIC) of vast lateral muscle. Temporal error was used as performance assessment and RMS to monitor muscular activation ${ }^{21}$. Temporal error was determined as the sum of the difference between the criterion of task execution concentric ( 2 seconds) and eccentric (4 seconds), as follows:

$$
\text { Temporal error }=\left[\left(\left|\mathbf{M}_{i}^{\text {conc }}-\mathbf{M} c^{\text {conc }}\right|\right)+\left(\left|\mathbf{M}_{i}^{\text {ecc }}-\mathbf{M} c^{\text {ecc }}\right|\right)\right]
$$


Where $\mathrm{M}_{i}$ conc is the actual movement time in concentric execution, $\mathrm{M}_{i}{ }^{\mathrm{ecc}}$ is the actual movement time in eccentric execution, $\mathrm{Mc}^{\text {conc }}$ is the temporal goal for the concentric execution and $\mathrm{Mc}^{\mathrm{ecc}}$ is the temporal goal for the eccentric execution.

RMS measures were analyzed in terms of mean, in blocks of six trials for each leg, and the mean of both legs in all experimental conditions. That is, legs EMG activity was not evaluated separately, but through the mean activation of both legs.

One-way analyses of variance (ANOVAs) with repeated measures on all variables were used for conditions comparisons. Post-hoc analyses were conducted using Tukey's test. An alpha level of 0.05 was set for all analyses. The effect sizes were calculated using eta-squared test $\left(\eta^{2}\right)$.

\section{RESULTS}

\section{Temporal error}

The ANOVA showed main effects for Conditions, $\mathrm{F}(2,10)=5.78, \mathrm{p}=$ $.02, \eta^{2}=.53$. Post hoc comparisons revealed that demonstration condition presented lower temporal error than external focus $(p=.02)$, but there was no significant difference between internal focus and the other conditions ( $p>.05$ ). Figure 2 depicts mean temporal error for all experimental conditions - internal focus, external focus and online demonstration.

In the analyses of RMS the ANOVA indicated main effects for Conditions, $\mathrm{F}(2,10)=5.90, \mathrm{p}=.03, \eta^{2}=.66$. Post hoc comparisons revealed that online demonstration condition showed lower average EMG activation than external focus $(\mathrm{p}=.03)$, but there was no significant difference between internal focus and the other conditions ( $p>.05)$. Figure 3 depicts average RMS under each experimental condition.

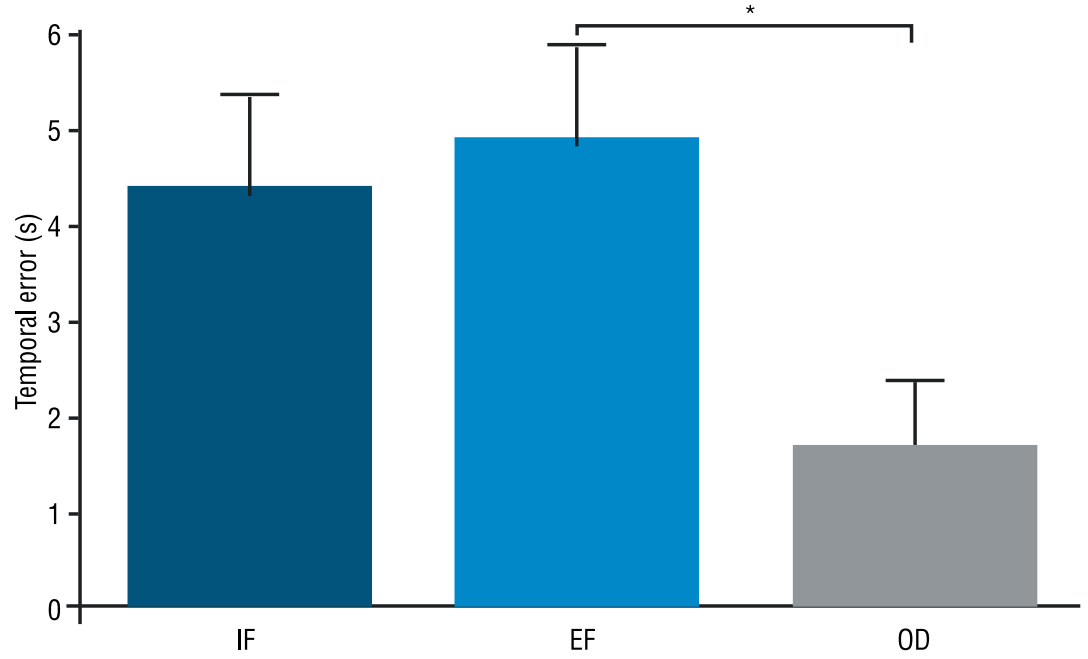

Figure 2. Mean and $+S D$ values of temporal error over the conditions.

Note: $\mathrm{IF}=$ internal focus. $\mathrm{EF}=$ external focus. $\mathrm{D}=$ online demonstration. ${ }^{*}=\mathrm{p}<0.05$.

RMS (\%) 


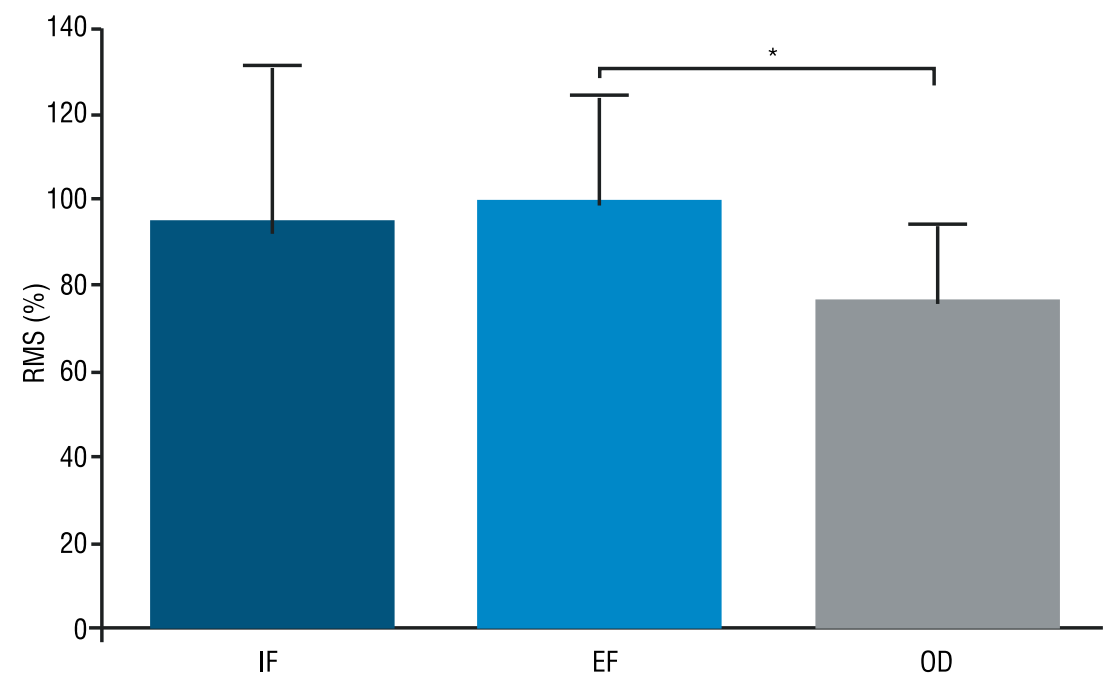

Figure 3. Mean and $+S D$ values of average EMG over the conditions Note: $\mathrm{IF}=$ internal focus. $E F=$ external focus. $D=$ online demonstration. ${ }^{*}=p<0.05$.

\section{DISCUSSION}

Although previous studies have already demonstrated the role of attentional focus in performance and production measures, this is the first study, to the authors' knowledge, to address the interaction between online demonstration and focus of attention. The present study aimed to examine whether there would exist performance (outcome measure) differences between external focus, internal focus and online demonstration conditions. Moreover, we aimed to examine whether these differences would be observed in a production measure. Results shows that online demonstration condition led to better performance than external focus condition in both outcome and production measures. However, differences between internal focus and the other experimental conditions were not found.

We hypothesized that under demonstration conditions participants would be more accurate than external and internal focus conditions. We also hypothesized that online demonstration condition would show smaller EMG activity than external and internal focus conditions. These hypotheses were partially confirmed, since the online demonstration condition led to better performance (outcome measure) and reduced RMS activity than external focus condition but not internal focus condition. Overall, results indicated that reduced neuromuscular activity is associated with increased performance, since better performance was found for online demonstration condition, which also presented smaller EMG activity. The reduced EMG activity obtained when participants directed attention towards the model in the video, in the online demonstration condition, might be understood as a greater economy in movement production. Since the weight lifted was the same under all conditions, a less active muscle means a more efficient movement control.

One possible explication for the superiority of online demonstration in both outcome and production measures may be related to the projection 
of the participant's attention to the model viewed on video, which is an external reference in relation to their bodies. Also, observing a model may have allowed participants the opportunity to identify the crucial aspects of a task ${ }^{23,24}$. The extraction of these crucial aspects allows participants not to excessively worry about aspects that are not crucial to task execution. Presumably, focusing in crucial aspects of the task decreased the conscious control of some degrees of freedom in the movement execution.

Although Constrained Action Hypothesis was elaborated to explain the advantages of focus on the movement effect, this explanation may also be suitable to explain the benefits found in the online demonstration condition of our study. As previously mentioned, the external focus induces a less conscious type of control, causing a smaller constrain in the individual's motor system compared to internal focus. One way to justify this hypothesis is by using automaticity measures, such as attentional-capacity demands ${ }^{11}$. It is expected that attentional-capacity demands would be reduced when individuals focus their attention externally, while the internal focus would lead to an additional processing resulting in increased attention demands and consequently decreased performance ${ }^{25}$. Our findings corroborate this prediction, as the observation of a model seems to have allowed the individual to identify the crucial aspects of the task. By guiding attention to the crucial aspects of the task, learners can reduce possible additional processing through the decrease of attentional demand and consequently liberate cognitive resources that may be used to improve motor performance.

Although we expected to replicate the benefits of the external focus over the internal focus condition, differences in outcome measures previously found in other studies that investigated attentional focus were not found. These results challenges the logic of the study. A possible explanation for this divergence in our study may be the inclusion of a third group in the statistical comparison, in this case the online demonstration condition. Adding one more group may have made it harder to identify differences in the external and internal focus comparison. However, even when only two groups were compared, other studies also did not find differences between internal and external focus of attention ${ }^{26,27}$.

Overall, the results of the present study extend those found in the literature concerning the neuromuscular level of analysis, and add another important contribution: the online demonstration as a way to direct learner's attention. It seems that providing online demonstration may be even more effective in directing individual's attention than external focus, both in terms of outcome and production measures. Perhaps one can think of a continuum in directing the attention from the innermost to the outermost, with the online demonstration placed more externally in relation to the external focus. As investigated by McNevin, Shea and Wulf ${ }^{25}$, increasing the distance of an external focus of attention is positively associated with performance. We understand that online demonstration is not associated with the individual's own movement production, which by itself is enough to exclude this manipulation off the external focus concept, however the 
evidence found for its effectiveness is promising and calls for future investigations.

As a possible limitation, the present study did not include a control condition without attentional focus instructions. Thus, it is unclear whether the internal focus, external focus and online demonstration conditions resulted in a reduction of muscular activity when compared to so-called regular conditions. That issue remains to be investigated in future studies. We also suggest that future studies should perform a previous assessment of the participant's capacity to drive his/her attention. Finally, the investigation of motor control mechanisms and phases that are part of motor control in tasks that require force control with different degrees of movement may be relevant in order to better understand the effects of the attentional focus conditions investigated.

The results of the present study add the online demonstration as a way to direct performer's attention, the practical appeal of these results for improving motor performance is undoubtedly high. However, one of the challenges faced by instructors is the translation of motor learning concepts and research into practical teaching applications ${ }^{28}$. The manipulations of important factors that have a strong reliance of visual information are usually present in teaching contexts involving tasks of resistance training. In resistance training, teaching a movement often begins with a demonstration on how to properly execute this movement ${ }^{29}$. The same is true for the role of the visual feedback available through a mirror. Visual feedback is the most prominent source of sensory information when performing complex motor tasks and the use of a mirror to provide feedback is efficient to gain strength in hip extensor, for example ${ }^{30}$. Practitioners (e.g., coaches, teachers and therapists) may combine the use of external focus of attention with visual feedback or concomitant demonstration to optimize performance in resistance exercises.

\section{CONCLUSION}

The results of our study suggest that online demonstration condition obtained better performance than external focus condition and a reduced muscular activation. However, differences between internal focus and the other experimental conditions were not found. These findings advance in the understanding mechanisms underpining the focus of attention, such as proposed by Wulf et al. ${ }^{2}$. Moreover, our study opens a new exciting field in the study of online demonstration.

\section{COMPLIANCE WITH ETHICAL STANDARDS}

\section{Funding}

This research did not receive any specific grant from funding agencies in the public, commercial, or not-for-profit sectors. 


\section{Ethical approval}

Ethical approval was obtained from the local Human Research Ethics Committee -F Federal University of Minas Gerais and the protocol (no. CAAE: 64956217.6.0000.5149) was written in accordance with the standards set by the Declaration of Helsinki.

\section{Conflict of interest statement}

The authors have no conflict of interests to declare.

\section{Author Contributions}

Conceived and designed the experiments: TAS, CEC, LTL, FDT. Performed the experiments: TAS, HU, CEC, LTL, FDT, LSF, GML. Analyzed the data: TAS, HU, CEC, LTL, FDT, LSF, GML. Contributed reagents/materials/analysis tools: TAS, HU, CEC, LTL, FDT, LSF, GML. Wrote the paper: TAS, HU, CEC, LTL, FDT, LSF, GML.

\section{REFERENCES}

1. Vidal A, Wu W, Nakajima M, Becker J. Investigating the Constrained Action Hypothesis: A Movement Coordination and Coordination Variability Approach. J Mot Behav 2017;0:1-10.

2. Wulf G, Höß M, Prinz W. Instructions for motor learning: Differential effects of internal versus external focus of attention. J Mot Behav 1998;30(2):169-79.

3. Manojlovic V, Erculj F. Impact of the focus of attention on vertical jump performance of junior basketball players. Fiz Kult 2013;67(1):61-7.

4. Wulf G, Su J. An External Focus of Attention Enhances Golf Shot Accuracy in Beginners and Experts. Res QExerc Sport 2007;78:37-41.

5. Silva MT da, Less HT, Chiviacowsky S. External Focus of Attention Enhances Children's Learning of a Classical Ballet Pirouette. J Danc Med Sci 2017;21:179-84.

6. Castaneda B, Gray R. Effects of Focus of Attention on Baseball Batting Performance in Players of Differing Skill Levels. J Sport Exerc Psychol 2007;29:60-77.

7. Wulf G, Planck M. Directing attention to movement effects enhances learning: A review. Psychon Bull Rev 2001;8(4):648-60.

8. Oki Y, Kokubu M, Nakagomi S. External Versus Two Different Internal Foci of Attention in Long- Distance Throwing. Percept Mot Skills 2017;0(0):1-13.

9. Fietzer AL, Winstein CJ, Kulig K. Changing one's focus of attention alters the structure of movement variability. Hum Mov Sci 2018;62:14-24.

10. Mornell A, Wulf G. Adopting an External Focus of Attention Enhances Musical Performance. J Res Music Educ 2018;1-17.

11. Wulf G, McNevin N, Shea CH. The automaticity of complex motor skill learning as a function of attentional focus. QJ Exp Psychol A 2001;54(4):1143-54.

12. Wulf G, Dufek JS, Lozano L, Pettigrew C. Increased jump height and reduced EMG activity with an external focus. Hum Mov Sci 2010;29(3):440-8.

13. Marchant DC, Greig M. Attentional focusing instructions influence quadriceps activity characteristics but not force production during isokinetic knee extensions. Hum Mov Sci 2017;52:67-73.

14. Zachry T, Wulf G, Mercer J, Bezodis N. Increased movement accuracy and reduced EMG activity as the result of adopting an external focus of attention. Brain Res Bull 2005;67(4):304-9.

15. Vance J, Wulf G, Töllner T, Mcnevin N, Mercer J, Wulf G, et al. EMG Activity as a Function of the Performer's Focus of Attention. J Mot Behav 2004;36:450-9. 
16. Williams AM, Davids K. Visual Search Strategy, Selective Attention, and Expertise in Soccer. Res QExerc Sport 1998;69(2):28-111.

17. Martens R, Burwitz L, Zuckerman J. Modeling Effects on Motor Performance Modeling Effects on Motor Performance. Res Q1976;47(2):277-91.

18. Ste-Marie DM, Law B, Rymal AM, Jenny O, Hall C, McCullagh P. Observation interventions for motor skill learning and performance: An applied model for the use of observation. Int Rev Sport Exerc Psychol 2012;5(2):145-76.

19. Wulf G, Raupach M, Pfeiffer F, Wulf G, Raupach M, Pfeiffer F. Self-Controlled Observational Practice Enhances. Res QExerc Sport 2005;76(1):37-41.

20. Wulf G, Shea C, Lewthwaite R. Motor skill learning and performance: A review of influential factors. Med Educ 2010;44(1):75-84.

21. Lacerda LT, Martins-Costa HC, Diniz RCR, Lima F V, Andrade AGP, Tourino FD, et al. Variations in Repetition Duration and Repetition Numbers Influence Muscular Activation and Blood Lactate Response in Protocols Equalized by Time Under Tension. J Strength Cond Res 2016;30(1):251-8.

22. Pincivero DM, Salfetnikov Y, Campy RM, Coelho AJ. Angle- and gender-specific quadriceps femoris muscle recruitment and knee extensor torque. J Biomech 2004;37:1689-97.

23. Carroll WR, Bandura A. Representational guidance of action production in observational learning: A causal analysis. J Mot Behav 1990;22(1):85-97.

24. Andrieux M, Proteau L. Observational Learning : Tell Beginners What They Are about to Watch and They Will Learn Better. Front Psychol 2016;7:1-9.

25. McNevin NH, Shea CH, Wulf G. Increasing the distance of an external focus of attention enhances learning. Psychol Res 2003;67(1):22-9.

26. Peh SY, Yi J, Davids K. Focus of attention and its impact on movement behaviour. J Sci Med Sport 2011;14(1):70-8.

27. Schorer J, Jaitner T, Wollny R, Fath F, Baker J. Influence of varying focus of attention conditions on dart throwing performance in experts and novices. Exp Brain Res 2012;217(2):287-97.

28. Boyce BA, Coker CA, Bunker LK. Implications for variability of practice from pedagogy and motor learning perspectives: Finding a common ground. Quest 2006;58(3):330-43.

29. Kompf J. Enhancing Skill and Performance in Resistance Training. Strength Cond J 2016;38.

30. Choi M, Yoo J, Shin S, Lee W. The effects of stepper exercise with visual feedback on strength, walking, and stair climbing in individuals following stroke. J Phys Ther Sci 2015;27(6):1861-4.

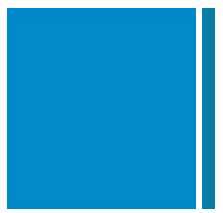

Corresponding author

Tércio Apolinário-Souza

Universidade do Estado de Minas Gerais

Departamento de Ciências do Movimento

Av. São Paulo (Rod MG 040 URB), 3996 - Vila Rosário, MG, 32412-190, Brasil

E-mail address: edf.tercio@hotmail.com 